\title{
Detecção de fraturas em poços horizontais usando a resposta do perfil de indução
}

\author{
Alfredo Carrasco, UFF/ TEQ - Niterói, RJ \& Abel Carrasquilla, UENF/LENEP - Macaé, RJ
}

Copyright 2016, SBGf - Sociedade Brasileira de Geofísica

Este texto foi preparado para a apresentação no VII Simpósio Brasileiro de Geofísica, Ouro Preto, 25 a 27 de outubro de 2016. Seu conteúdo foi revisado pelo Comite Técnico do VII SimBGf, mas não necessariamente representa a opinião da SBGf ou de seus associados. É proibida a reprodução total ou parcial deste material para propósitos comerciais sem prévia autorização da SBGf.

\section{Resumo}

A perfuração de um poço pode provocar fraturas cujas direções de propagação dependem das tensões existentes. Num poço horizontal, a distribuição de tensões é diferente nos planos vertical e horizontal. Com a finalidade de avaliar a possível detecção dessas fraturas em poços horizontais, simulamos as respostas do perfil resistivo de indução profunda (ILD) e média (ILM) usando as técnicas da equação integral e dos elementos finitos. Os resultados indicam respostas mais evidentes em fraturas maiores, com ILM sendo mais sensível com fraturas próximas e ILD com as afastadas, por causa das diferentes focalizações devido as diferentes profundidades de investigação.

\section{Introdução}

A necessidade de se perfurar poços horizontais é reconhecida há muito tempo e entre as principais razões encontram-se o aumento da área exposta ao fluxo de hidrocarbonetos, o que reduz os problemas ocasionados por cone de água e de gás, e principalmente na perfuração de reservatórios fraturados. Neste último caso, as rochas carbonáticas tendem a apresentar baixa porosidade primária e normalmente apresentam fraturas verticais que são ideais para serem interceptadas por poços horizontais. Exemplos deste tipo de reservatório são o Austin Chalk no sul de Texas, o Rospo Mare na Itália, etc., como mostrado na Figura 1 (Rocha et al., 2011).

Os perfis geofísicos de imagem resistivas FMI (Formation Micro Imager) tem sido usados com bastante frequência para detectar estruturas geológicas correlacionadas com a existência de fraturas, acamamentos, etc. na parede de poços verticais ou horizontais. Fraturas podem ser detectadas pela diferença entre as resistividades da lama que a preenche e a da formação numa imagem FMI através do contraste de cores, com as áreas resistivas aparecendo em cores claras e as condutivas nas escuras (Ribeiro et al., 2006). Como exemplo mostramos na Figura 2 o perfil de imagem do poço horizontal Barnett, perfurado na direção do esforço horizontal mínima. Nessa figura notamos linhas azuis relacionadas com fraturas induzidas durante perfuração, assim como linhas escuras associadas com fraturas naturais verticais e horizontais (Waters et al., 2006).

O fato de orientar o eixo do poço na direção da tensão horizontal mínima é importante, pois nesta situação são obtidas fraturas verticais transversais se propagando na direção da tensão horizontal máxima (Figura 3). Caso a seção do poço horizontal seja perfurada na direção da tensão horizontal máxima (Figura 4), será obtida uma fratura longitudinal ao longo do seu eixo, o que não seria recomendável, pois se estaria atingindo as zonas de gás ou água do reservatório (Rocha \& Azevedo, 2009)

Para avaliar a dimensão de fraturas desse tipo, neste trabalho utilizamos simulações numéricas que objetivam observar a sua influência delas nas respostas do perfil de indução, o que facilitaria as suas localizações num poço horizontal que atravessa um reservatório carbonático. De fato, os carbonatos são caracterizados por ser uma rocha relativamente dura, mas com características de fragilidade, motivo este que faz criar fraturas com facilidade. Por tanto, se faz necessário um entendimento destes efeitos nas respostas do perfil de indução, o qual propomos estudar neste trabalho a partir de simulações numéricas.

\section{Metodologia}

Inicialmente, utilizando o fato de que as fraturas podem ser detectadas numa imagem FMI, utilizamos os trabalhos de Talabani et al. (2005) e Waters et al. (2006) para nos orientarmos na escolha de um modelo de fraturas mais próximo da realidade num poço horizontal. $\mathrm{Na}$ Figura 2, observamos que existe uma alta frequência de fraturas verticais (transversais à direção do poço) presentes na imagem desse tipo de poço, as quais serão as únicas que passaremos a considerar no nosso modelo.

Para desenvolver o nosso estudo, utilizamos os perfis ILD e ILM e as técnicas numéricas de elementos finitos (Cozzolino, 2004) e da equação integral (Carrasco, 2004), para simular diferentes cenários da presença de fraturas verticais. Nos modelos consideramos um poço horizontal atravessando uma geologia com geometria tridimensional e as fraturas com formato elíptico cortando-o perpendicularmente (Figura 3). $O$ raio assumido para o poço horizontal é $0.1 \mathrm{~m}$, com resistividade de 0.5 ohm.m para a lama de perfuração. Nos extremos do poço horizontal foi considerada a presença de folhelhos segundo a trajetória correspondente a um poço real (Figura 5). Por outro lado, a invasão de fluidos dentro do meio poroso não foi considerada, somente dentro das fraturas, considerando um reservatório com baixa porosidade primária. Assim, nos modelos simulados as fraturas com formato elipsoidal apresentam um raio menor de $0.3 \mathrm{~m}$ e raio maior de 0.7 ou $1.2 \mathrm{~m}$, com afastamentos de 1 ou $3 \mathrm{~m}$ entre elas.

\section{Resultados}

Para o primeiro modelo, consideramos duas fraturas com afastamento de $1 \mathrm{~m}$, localizadas em distancias horizontais de $-0.5 \mathrm{~m}$ e $0.5 \mathrm{~m}$, com raios elipsoides de 0.3 e $0.7 \mathrm{~m}$ e camada com resistividade de 800 ohm-m, 
supondo que contem hidrocarbonetos. Para esse modelo, as respostas das ferramentas de ILM e ILD aparecem na Figura 6. Na figura, a linha tracejada, que representa o modelo sem fraturas para ambas ferramentas, está superposta com o modelo com fraturas no perfil ILD e com uma leve separação para o perfil ILM. Observa-se, portanto, que nessa condição é difícil observar as fraturas, quiçá pela diferença de tamanhos entre a dimensão das ferramentas e a separação entre fraturas, sendo o perfil ILM o que melhor registra a presença delas.

No segundo modelo, foi modificada o tamanho da fratura do elipsoide para $0.3 \mathrm{~m}$ para $1.2 \mathrm{~m}$. As respostas para os dois perfis aparecem na Figura 7 , com as fraturas localizadas no eixo horizontal de $-0.5 \mathrm{~m}$ e $0.5 \mathrm{~m}$. Nesta figura, a separação entre as curvas do modelo sem fraturas (linhas tracejadas) e o modelo com fraturas (linhas continuas) é mais pronunciado que no caso anterior em ambos perfis, mas ainda com o perfil ILM focalizando e registrando melhor a presença das fraturas.

Finalmente, foi simulado um último modelo, onde a Figura 8 mostra as respostas dos dois perfis, quando as duas fraturas estão separadas $3 \mathrm{~m}$, estando localizadas nos pontos -1.5 e $1.5 \mathrm{~m}$, com as mesmas dimensões elipsoidais do modelo anterior (0.3 e $1.2 \mathrm{~m})$. Essa figura mostra também que o perfil ILD, neste caso, registra melhor que o perfil ILM a separação das curvas entre o modelo sem fraturadas (linhas tracejadas) e o modelo com fraturas (linhas contínuas), focalizando quiçá melhor as fraturas.

\section{Conclusões}

Os resultados deste trabalho mostram que as respostas das resistividades ficam mais evidentes quando 0 comprimento da fratura é maior. Entretanto, quando a separação entre as fraturas é menor, os resultados mostram que o perfil ILM tem maior sensibilidade que o ILD, pelo seu menor poder de investigação, pois o processo de indução eletromagnética seria mais forte nas proximidades da parede do poço. Também, é notório que quando existe um maior afastamento entre as fraturas, as respostas delas ficam evidenciadas com maior eficiência no perfil ILD, quiçá pelo maior poder de investigação que consegue focalizar melhor a posição das fraturas.

\section{Agradecimentos}

À UENF e a UFF pelo suporte computacional, à SPE por disponibilizar artigos para consulta e SCTC/Petrobras pelo suporte financeiro de projeto de pesquisa.

\section{Referências}

Carrasco, A. 2004. Modelagem tridimensional da resposta de sondas de indução em ambientes geológicos complexos, utilizando equações integrais como técnica de modelagem numérica. Tese de Doutorado, LENEP/UENF, Macaé/RJ, 119 pp.
Cozzolino, K. 2004. Estudo dos efeitos transientes de temperatura e invasão em perfis de poço. Tese de Doutorado, UFRJ, Rio de Janeiro, 146 p.

Ribeiro, M.; Neaimi, M.; Hendrawan, I.; Karrani, S.; Saad, M.; Ayoub, M.; Zubair, K.; Marzouqui, K. \& Khoori, S. 2008. Real-time image data for successful horizontal drilling in carbonate reservoir onshore Abu Dhabi, UAE. Abu Dhabi International Petroleum Exhibition and Conference, 5-8 November, Abu Dhabi, UAE, SPE101916-MS.

Rocha, L.; Azuaga, D.; Andrade, R.; Vieira, J. \& Santos, O. 2011. Perfuração direcional. Editora Interciência, Rio de Janeiro. ISBN: 9788571932142, 234 p.

Rocha, L. \& Azevedo, C. 2009. Projeto de poços de petróleo, geopressões e assentamento de colunas de revestimentos. Editora Interciência, Rio de Janeiro, 562 p.

Talabani, S.; Efnik, M.; Baradi, A. \& Salim, B. 2005. A new technique in acquiring high quality image logs in deviated \& horizontal wells: Case History. SPE Middle East Oil and Gas Show and Conference, 12-15 March, Kingdom of Bahrain, SPE-92889-MS

Vernon, G.K., Karst, J., \& McKay, S.B. 1993. Successful applications of horizontal-well induction modeling. 34th annual logging symposium transactions: Society of Professional Well Log Analysts, Paper G, 12 p.

Waters, G.; Heinze, J.; Jackson, R.; Ketter, A.; Daniels, J. \& Bentley, D. 2006. Use of horizontal well image tools to optimize Barnett Shale reservoir exploitation. SPE Paper No. 103202. Proceedings of the SPE Annual Conference and Exhibition, San Antonio, Tx, USA. 


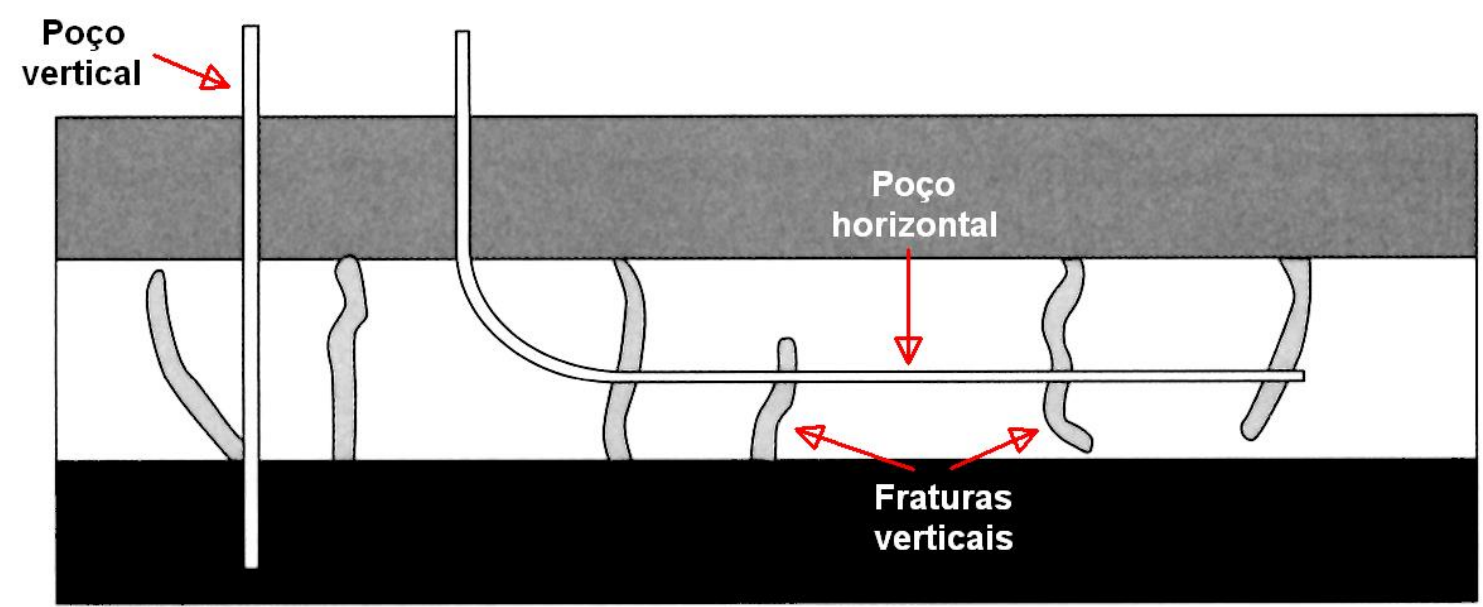

Figura 1. Fraturas verticais naturais (em cinza) presentes num reservatório carbonático e atravessadas por um poço horizontal, com pouco contato com o poço vertical (modificado de Rocha et al, 2011).

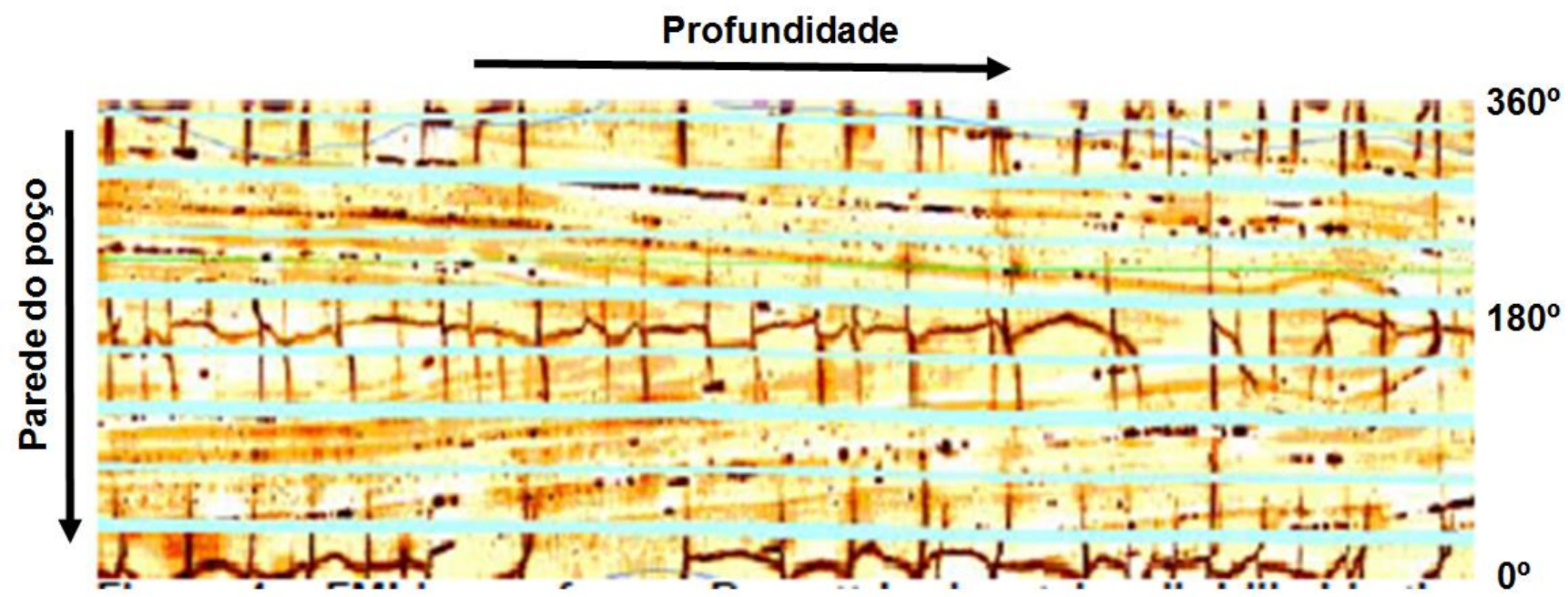

Figura 2. Perfil Imagem FMI aplicado na seção horizontal no reservatório Barnett (Waters et al., 2006). As linhas horizontais azuis são marcas de ferramentas de perfuração o de perfilagem e as escuras são fraturas horizontais e verticais. 


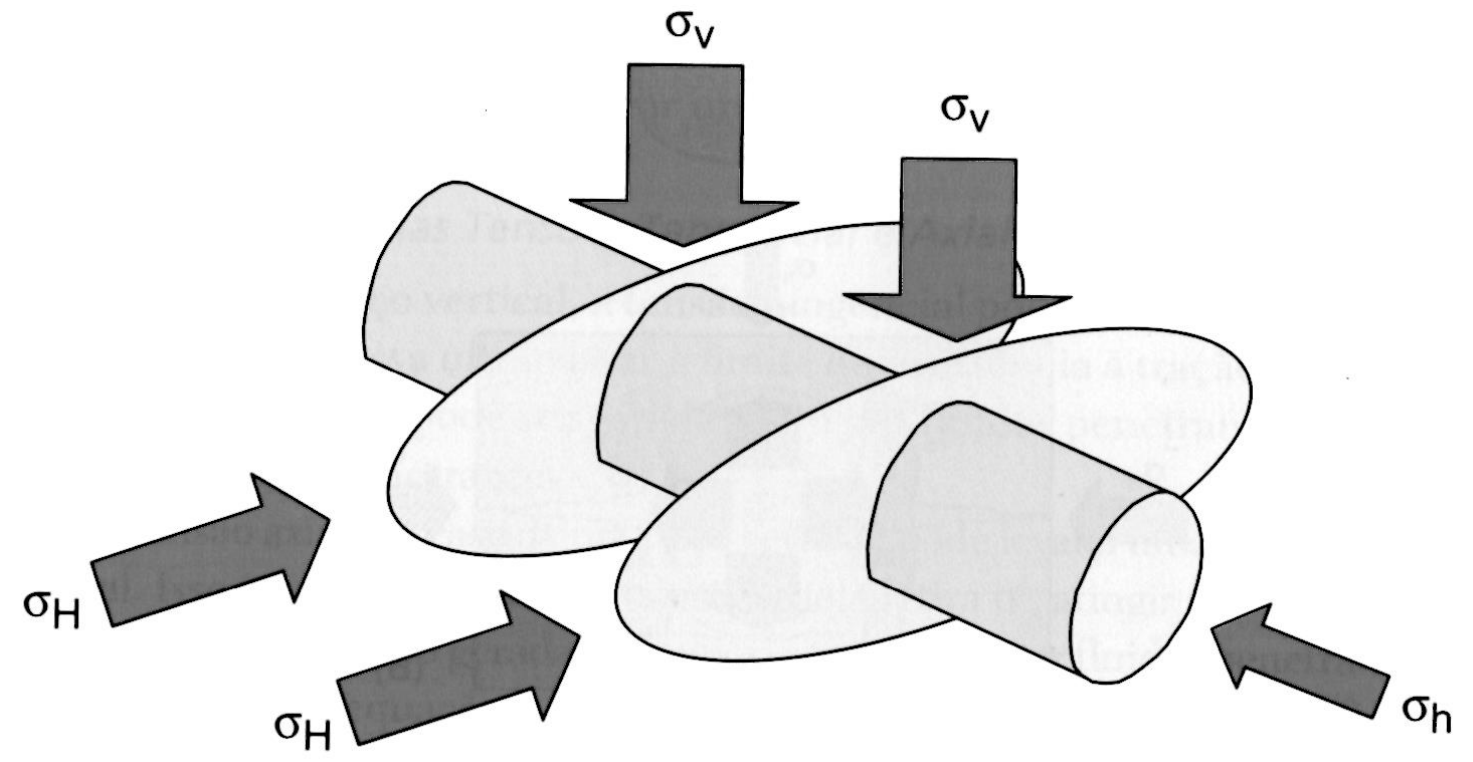

Figura 3. Poço horizontal perfurado na direção da tensão horizontal mínima (Rocha \& Azevedo, 2009)

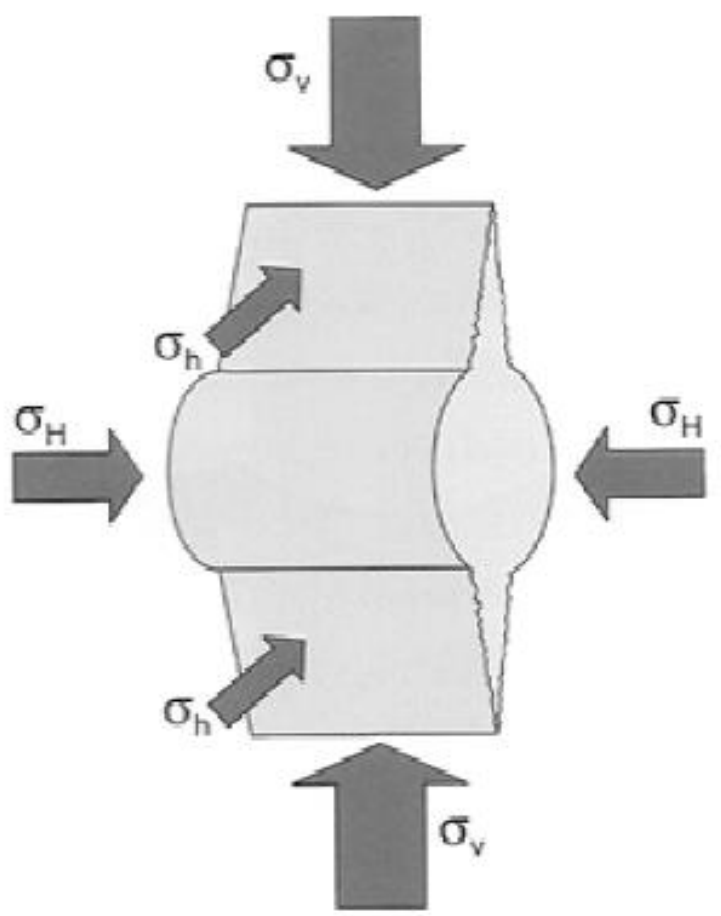

Figura 4. Poço horizontal perfurado na direção da tensão horizontal máxima (Rocha \& Azevedo, 2009) 


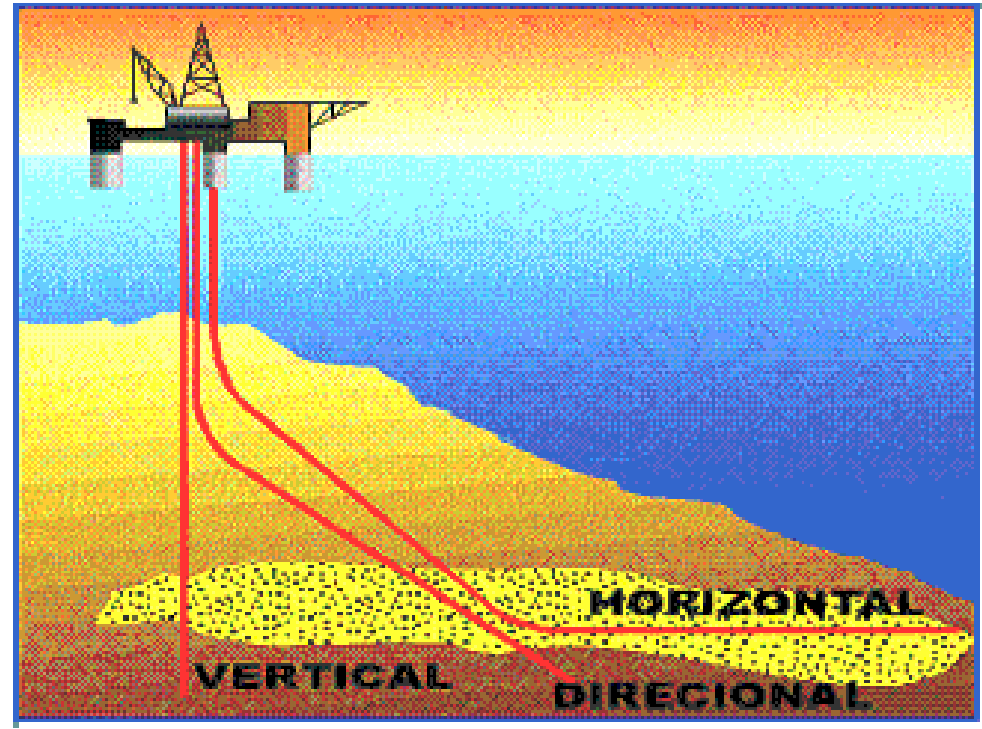

Figura 5. Trajetória de um poço horizontal (modificado de Vernon et al., 1993).

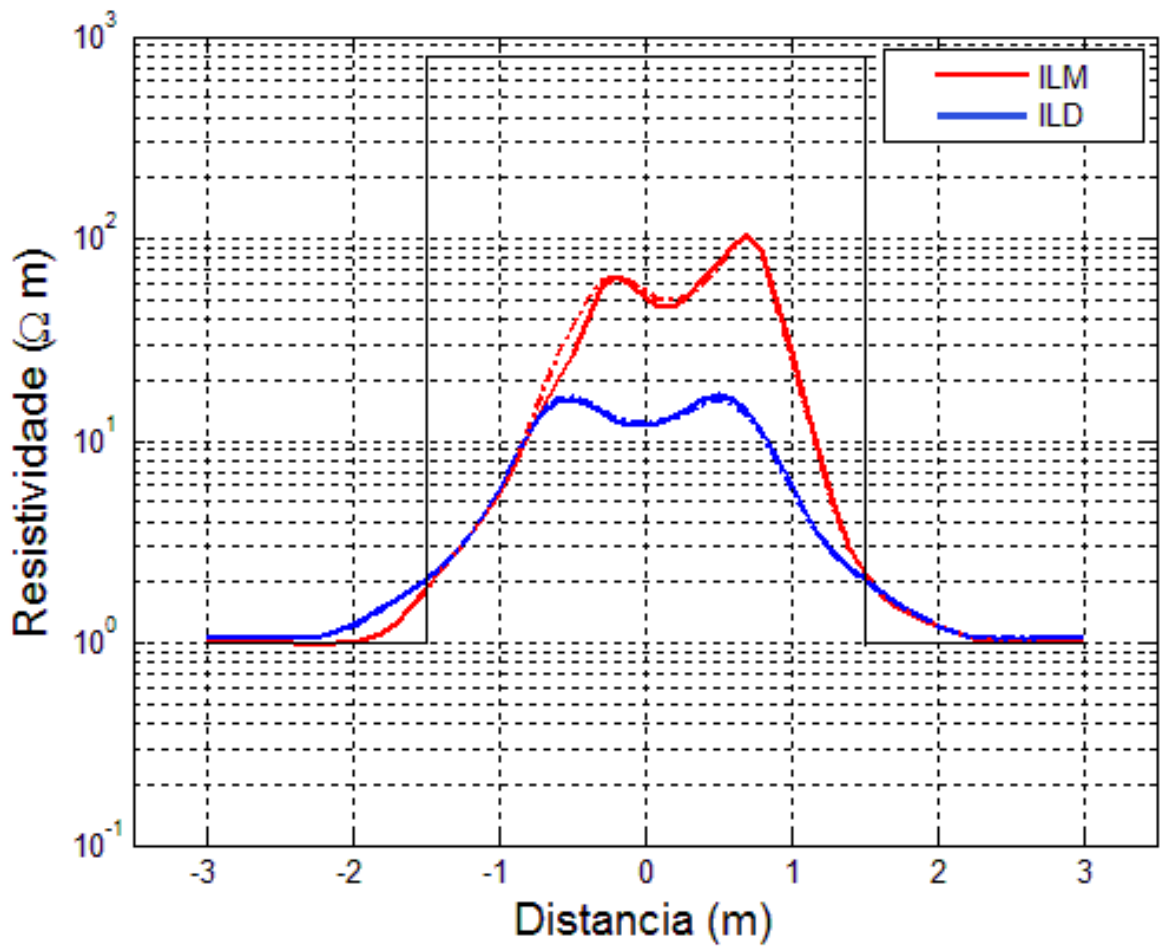

Figura 6. Duas fraturas com afastamento de $1 \mathrm{~m}$ entre elas, localizadas em distancias horizontais de $-0.5 \mathrm{~m}$ e $0.5 \mathrm{~m}$, com raios elipsoides de 0.3 e $0.7 \mathrm{~m}$ e camada com resistividade de 800 ohm-m. 


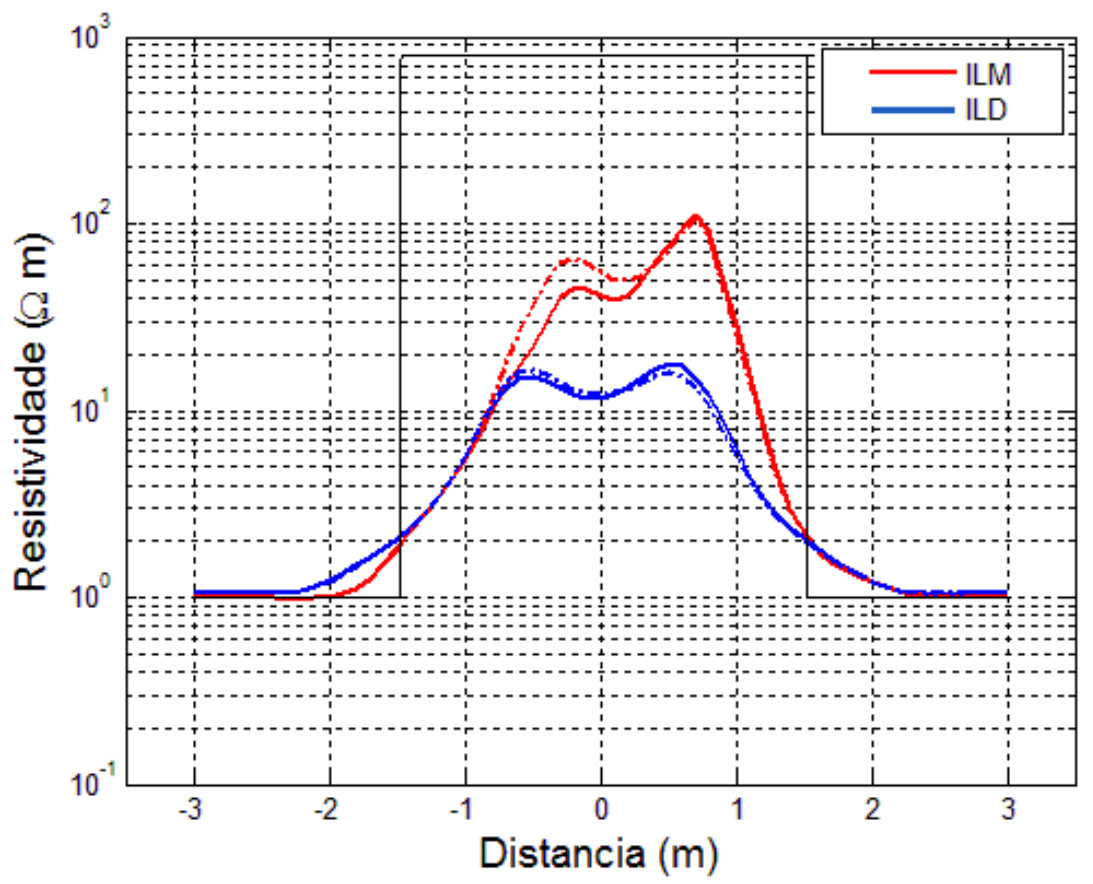

Figura 7. Duas fraturas com afastamento de $1 \mathrm{~m}$ entre elas, localizadas em distancias horizontais de $-0.5 \mathrm{~m}$ e $0.5 \mathrm{~m}$, com raios elipsoides de 0.3 e $1.2 \mathrm{~m}$ e camada com resistividade de 800 ohm.m.

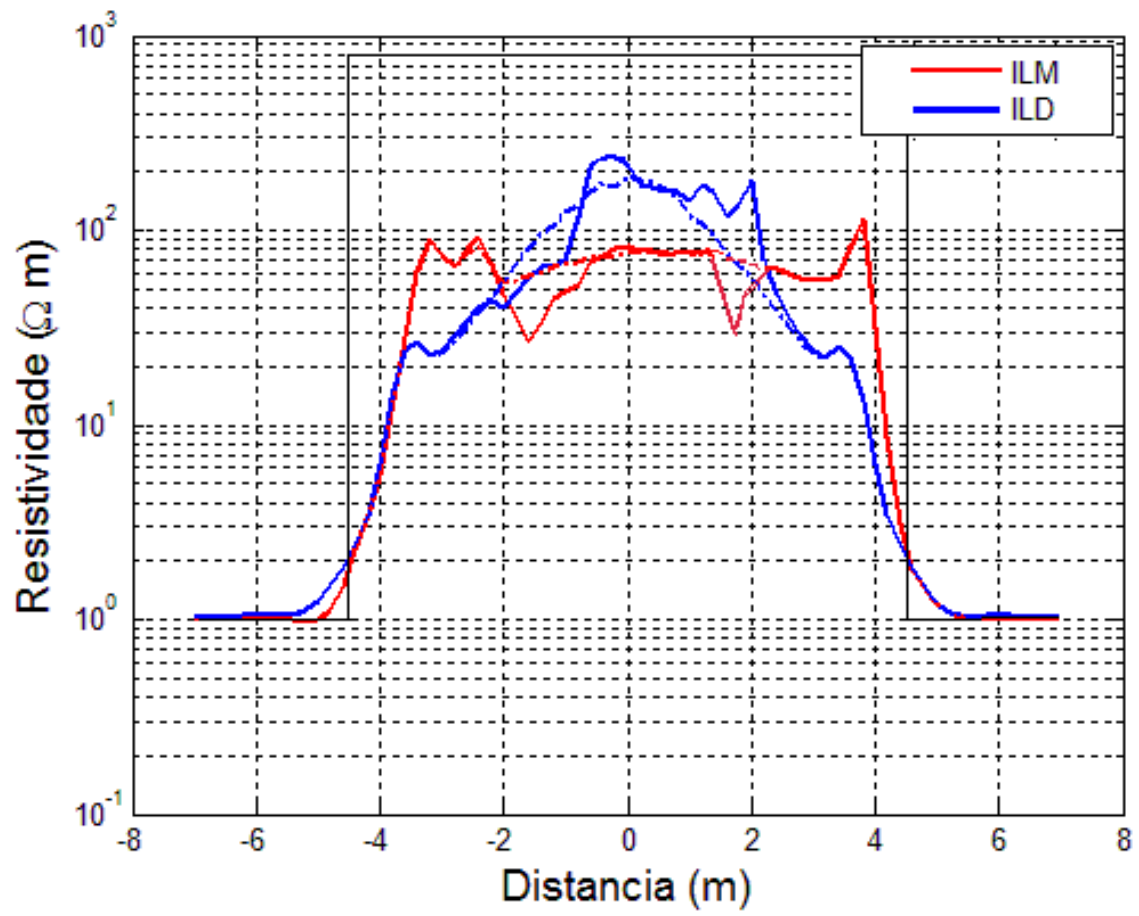

Figura 8. Duas fraturas com afastamento de $3 \mathrm{~m}$ entre elas, localizadas em distâncias horizontais de -1.5 $\mathrm{m}$ e $1.5 \mathrm{~m}$, com raios elipsoides de 0.3 e $1.2 \mathrm{~m}$ e camada com resistividade de 800 ohm.m. 